\title{
Coerced First Intercourse and Reproductive Health Among Adolescent Women in Rakai, Uganda
}

By Michael A. Koenig,

Iryna Zablotska,

Tom Lutalo,

Fred Nalugoda,

Jennifer Wagman

and Ron Gray

Michael A. Koenig is associate professor, Iryna Zablotska is a doctoral candidate and Ron Gray is pro-

fessor, all at the

Department of

Population and

Health Sciences,

Bloomberg School of

Public Health, Johns

Hopkins University,

Baltimore, MD, USA.

Tom Lutalo is data manager, Fred Nalugoda is director of field activities and

Jennifer Wagman is social science adviser,

all at the Rakai

Health Sciences Program, Uganda Virus

Research Institute,

Entebbe, Uganda.

\begin{abstract}
CONTEXT: Although there is increasing recognition of the scope and significance of sexual coercion experienced by adolescent women in developing countries, evidence on its consequences for reproductive health remains limited.
\end{abstract}

METHODS: A sample of 575 sexually experienced 15-19-year-old women were interviewed in 2001-2002 as part of the ongoing Rakai surveillance project in rural Uganda. Chi-square tests and logistic regressions were used to investigate associations between coerced first intercourse and selected reproductive health behaviors and outcomes.

RESULTS: Fourteen percent of young women reported that their first sexual intercourse had been coerced. After the effects of respondents' demographic characteristics were accounted for, young women who reported coerced first intercourse were significantly less likely than those who did not to be currently using modern contraceptives, to have used condoms at last intercourse and to have used them consistently during the preceding six months; they were more likely to report their current or most recent pregnancy as unintended (among ever-pregnant women) and to report one or more genital tract symptoms.

CONCLUSIONS: Coerced first intercourse is an important social and public health problem that has potentially serious repercussions for young women's reproductive health and well-being. Interventions to improve adolescent women's reproductive health should directly address the issue of sexual coercion.

International Family Planning Perspectives, 2004, 30(4):156-163

Over the past decade, the issue of domestic violence has received increasing international recognition and attention. The World Health Organization defines domestic violence as "the range of sexually, psychologically and physically coercive acts used against adult and adolescent women by current or former male intimate partners." growing awareness of the importance of sexual violence and coercion as a component of overall domestic violence.

Most research on sexual violence is based on data from reproductive-age women in intimate partnerships. Studies have indicated high rates of nonconsensual intercourse in developing countries, where as many as one-fifth to onehalf of all female respondents report having been coerced into sexual intercourse by an intimate partner. ${ }^{2}$ However, comparatively few studies from developing countries have explored the prevalence of sexual abuse and coercion specifically among adolescent women.

One indication that sexual violence is common among female adolescents is the substantial proportion of women who report that their first sexual intercourse (also referred to as "first sex" in this article) was coerced; this finding has been documented by a number of studies, although definitions of coercion have varied. Although the reported prevalence of coerced first sex is relatively low (less than $10 \%$ ) in several developed and developing country studies, ${ }^{3}$ in a number of other studies, largely from SubSaharan Africa, it typically ranged from $20 \%$ to $30 \%$ of all women ${ }^{4}$ and in some cases exceeded $40 \%{ }^{5}$ These quanti- tative results have been reinforced by qualitative findings from Sub-Saharan Africa that underscore the important role that coercion frequently plays in compelling young women to engage in sexual intercourse. ${ }^{6}$

Concern over the issue of coerced sex among adolescent women has been elevated by a growing body of researchmuch of it from developed countries-that has reported significant associations between coerced sex and a range of negative health and reproductive health outcomes for women of reproductive age. ${ }^{7}$ One of the strongest associations to emerge from the literature is the link between sexual abuse and the risk of unintended pregnancy, a relationship found in a number of studies from the United States. ${ }^{8}$ Studies from South Africa, Tanzania and India have also found a significant association between physical violence and coerced sex and the occurrence of unintended pregnancy. ${ }^{9}$ Other relevant work has documented a reduced likelihood of contraceptive use among women who have prior or current exposure to physical or sexual abuse by an intimate partner, or who are afraid of such violence. ${ }^{10}$

Other studies from developed countries have reported a significant link between physical or sexual abuse among reproductive-age women and a range of gynecological problems, including vaginal bleeding, pain during intercourse, chronic pelvic pain, urinary tract infection and medically treated pelvic inflammatory disease. ${ }^{11}$ Another set of studies has highlighted the possible association between women's experience of physical or sexual violence 
and their risk of contracting a sexually transmitted infection (STI), ${ }^{12}$ including HIV; ${ }^{13}$ in several studies from SubSaharan Africa, HIV-positive women were significantly more likely to report prior physical abuse or coerced sex than were HIV-negative women. ${ }^{14}$ Consistent with these results are findings from U.S. studies that indicate elevated levels of sexual risk behavior among women who have experienced coerced sex, ${ }^{15}$ along with decreased levels of condom negotiation or use. ${ }^{16}$

Evidence concerning the reproductive health sequelae of physical and sexual violence thus remains limited and has been drawn largely from studies in the United States or other developed countries. Moreover, most studies have focused on women of all reproductive ages rather than on adolescents specifically. Many of the existing studies have also used data from special, high-risk populations rather than from more broadly representative samples. Finally, existing studies display substantial variability in methodological rigor with respect to study design and controls for potentially confounding risk factors.

Data collected in rural Uganda in 2001-2002 provide a unique opportunity to explore in greater depth the issue of coerced sex and its reproductive health sequelae among young women in a community-based sample. In this paper, we present findings on the linkages between coerced first sex and selected reproductive health behaviors and outcomes in a sample of 575 sexually experienced adolescent women.

\section{METHODS}

\section{Setting and Data}

The setting for this study is rural Uganda. Premarital sex is common in Uganda and is a widely accepted behavior for young people of both genders. ${ }^{17}$ One-quarter of Ugandan women have had sex by age 15 , and two-thirds have done so by age $18 ;{ }^{18}$ a significant proportion initiate sex prior to marriage. ${ }^{19}$ Although many young women's sexual relationships appear to be volitional, some qualitative evidence from Uganda suggests that force and coercion may also frequently be a factor. ${ }^{20}$

Data for the present study came from the ongoing Rakai Project, which was started in 1987 as a collaborative intervention research initiative to understand and reduce HIV transmission in rural Uganda. Rakai, a rural district in southwestern Uganda that borders Tanzania and Lake Victoria, has been at the center of the country's HIV/AIDS epidemic, with an estimated HIV prevalence of $16 \%$ in the mid-1990s. ${ }^{21}$ In 1994, 56 communities located on secondary roads in Rakai were randomly selected and aggregated into 10 clusters; each cluster was randomly assigned to an intervention arm, which received mass STI treatment, or to a control arm. ${ }^{* 22}$ Interviews were conducted in respondents' homes at regular 10-month intervals and included a detailed questionnaire that collected data on demographic characteristics, health status and sexual behavior and partnerships. Respondents were also asked to provide blood and urine samples to be tested for HIV and selected STIs. All participants in both arms were educated about HIV, other STIs and family planning; given condoms free of charge; and provided with HIV test results, HIV/STI counseling, and treatment for general health problems and STIs on request. ${ }^{23}$ No financial incentives were provided to respondents for their participation in the study. The study was approved by one institutional review board in Uganda and two in the United States.

Between March 2001 and February 2002, all 15-49-yearold women who had been enrolled in the Rakai surveillance system prior to the 2001-2002 round were asked a series of questions concerning their experience of physical and sexual violence during their lifetime and in the last 12 months. ${ }^{24}$ Respondents were specifically asked whether force had been used the first time they had sex. Those who replied affirmatively were asked about the specific actions (both verbal and physical) that accompanied coercion at first sex. Respondents were also asked how willing they had been to engage in sex the first time. In this study, all women who reported that force had been used to compel them into first intercourse were classified as having had coerced first sex. ${ }^{\dagger}$ The 2001-2002 survey round also collected information on current use of contraceptives, pregnancy history, experience with unintended pregnancy, lifetime number of sexual partners, condom use at last sex, consistency of condom use in the last six months, and current symptoms of STIs and genital tract morbidity.

Procedures carefully established over the last decade in the Rakai Project for the collection of sensitive information included safeguards to protect the confidentiality of information provided by respondents and to minimize potential risks associated with participation in the study. Consent to participate was obtained from all respondents at enrollment and at each follow-up contact. Interviews were conducted in complete privacy by highly trained, same-sex interviewers, and no information from the survey was disclosed to respondents' family members. Completed questionnaires were kept in secure facilities, and interview schedules were coded with participants' study identification; no personal identifiers were included. In 2001-2002, only limited domestic violence services existed in this rural setting, but the Rakai Project has subsequently expanded both violence prevention efforts and counseling and support services for abused women.

Our primary study population consisted of all sexually experienced women who were aged 15-19 at the time of the 2001-2002 survey, had been enrolled in the surveillance system prior to this round, ${ }^{\dagger}$ and provided informa*In 1999, 12 communities from the original Rakai surveillance area were
dropped, and 12 new communities were added.

†This measure exhibited a high level of internal consistency with the measure of how willing respondents had been to have sex the first time: Eighty-four percent of young women who reported that their first sexual experience had been coerced also stated that they had been unwilling to engage in sex at that time.

fNew entrants into the surveillance system-many of whom had recently turned 15-were interviewed separately and not included in the followup survey; as a result, newly sexually active women may be underrepresented. 
FIGURE 1. Among sexually experienced women aged 15-19, percentage who reported having experienced sexual coercion in the 12 months preceding the survey, by experience of coerced first sex, according to cumulative number of partners

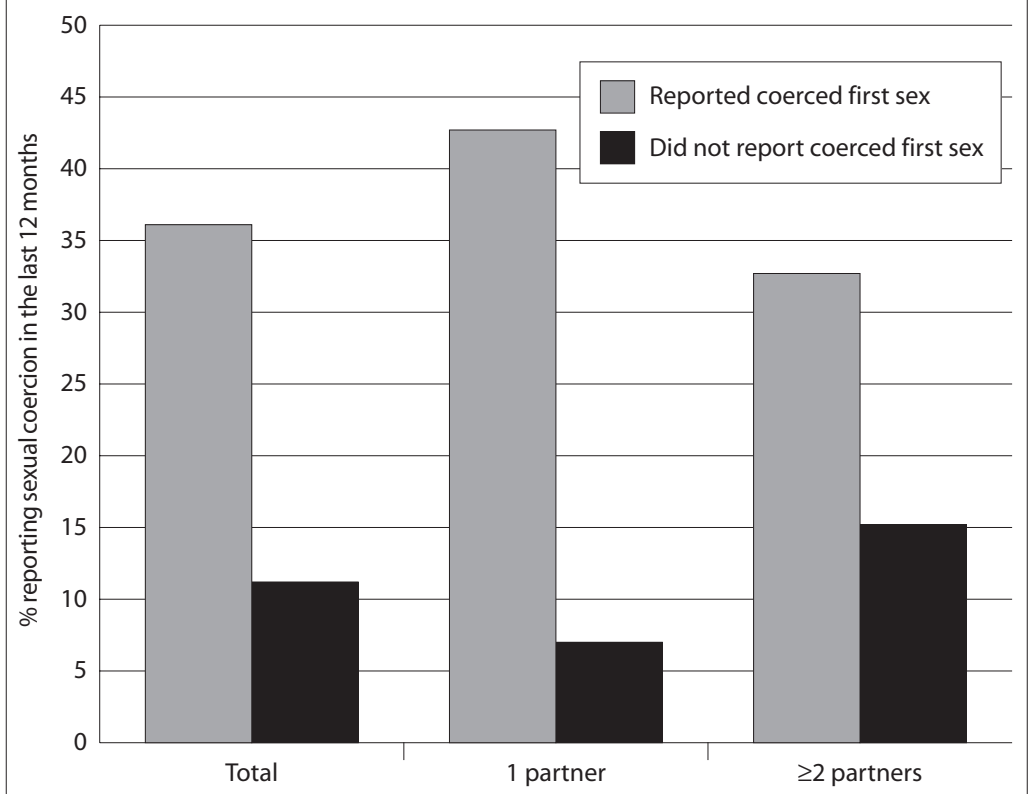

Note: Difference between those who reported coerced first sex and those who did not was significant at $p \leq .01$ for each comparison.

tion on their first sexual intercourse. These selection criteria yielded a sample of 575 young women.

\section{Statistical Analysis}

We used Pearson chi-square tests to assess significant differences in the prevalence of reproductive health outcomes among women who reported coerced first sex and among those who did not. We used multivariate logistic regressions, stratified by marital status, to evaluate associations between coerced first intercourse and dichotomous variables

TABLE 1. Percentage distributions of sexually experienced Ugandan women aged 15-19, by selected measures of reproductive behavior, according to marital status and experience of coerced first sex

\begin{tabular}{|c|c|c|c|c|c|c|}
\hline \multirow[t]{3}{*}{ Measure } & \multicolumn{2}{|l|}{ All } & \multicolumn{2}{|l|}{ Married } & \multicolumn{2}{|c|}{ Unmarried } \\
\hline & \multicolumn{2}{|c|}{ Coerced first sex } & \multicolumn{2}{|c|}{ Coerced first sex } & \multicolumn{2}{|c|}{ Coerced first sex } \\
\hline & Yes & No & Yes & No & Yes & No \\
\hline Current contraceptive use & $(\mathrm{N}=83)$ & $(\mathrm{N}=492)$ & $(\mathrm{N}=46)$ & $(\mathrm{N}=\mathbf{2 4 9})$ & $(\mathrm{N}=37)$ & $(\mathrm{N}=243)$ \\
\hline Yes & 18.1 & 33.5 & 8.7 & 17.7 & 29.7 & 49.8 \\
\hline No & 81.9 & 66.5 & 91.3 & 82.3 & 70.3 & 50.2 \\
\hline$\chi^{2} p$-value & .005 & & .130 & & .023 & \\
\hline Ever pregnant & $(\mathrm{N}=82)$ & $(\mathrm{N}=492)$ & $(\mathrm{N}=45)$ & $(\mathrm{N}=\mathbf{2 4 9})$ & $(\mathrm{N}=37)$ & $(\mathrm{N}=243)$ \\
\hline Yes & 80.5 & 64.6 & 100.0 & 97.2 & 56.8 & 31.3 \\
\hline No & 19.5 & 35.4 & 0.0 & 2.8 & 43.2 & 68.7 \\
\hline$\chi^{2} p$-value & .005 & & .255 & & .002 & \\
\hline $\begin{array}{l}\text { Intendedness of current or } \\
\text { most recent pregnancyt }\end{array}$ & $(\mathrm{N}=66)$ & $(\mathrm{N}=316)$ & $(\mathrm{N}=45)$ & $(\mathrm{N}=242)$ & $(\mathrm{N}=21)$ & $(\mathrm{N}=74)$ \\
\hline Intended & 40.9 & 58.5 & 46.7 & 64.9 & 28.6 & 37.8 \\
\hline Unintended & 51.5 & 36.7 & 44.5 & 29.3 & 66.7 & 60.8 \\
\hline No preference & 7.6 & 4.8 & 8.9 & 5.8 & 4.8 & 1.4 \\
\hline$\chi^{2} p$-value & .031 & & .069 & & .500 & \\
\hline Total & 100.0 & 100.0 & 100.0 & 100.0 & 100.0 & 100.0 \\
\hline
\end{tabular}

designed to measure reproductive health behaviors and outcomes: current use of modern contraceptive methods, ${ }^{*}$ condom use at last intercourse, consistent condom use with all partners during the last six months, reporting one or more current genital tract symptoms and, among ever-pregnant women, reporting the current or most recent pregnancy as unintended (i.e., mistimed or unwanted). The following demographic characteristics were included as categorical variables in all adjusted regression models: educational level (fewer than five years of schooling, 5-7 years and eight or more years), age at first intercourse (younger than 14, 14-15 and 16 or older), religious affiliation (Catholic, Muslim or other) and current marital status (marriage was defined as either legal or consensual union). The statistical package of STATA 8.1 was used for all analyses. ${ }^{25}$

\section{RESULTS}

Overall, 19\% of young women had had fewer than five years, 49\% had had 5-7 years and 33\% had had eight or more years of schooling. Nineteen percent reported that they were still attending school; thus, levels of education ultimately attained are likely to be somewhat higher than the levels reported in the survey. Roughly three in five participants were Catholic, one in five were Muslim, and the remainder reported other religious affiliations. In this population of sexually experienced young women, 13\% said that they had first had sex before the age of $14,46 \%$ at age 14 or 15 , and $41 \%$ at age 16 or older. At the time they were interviewed, $52 \%$ of women were married, $44 \%$ were never-married and 4\% were previously, but not currently, married.

\section{Prevalence of Coerced First Sex}

Fourteen percent of all respondents reported that their first sexual intercourse had been coerced (not shown). The likelihood of a respondent's first intercourse having been coerced was strongly associated with the age at which it occurred: Although 26\% of young women who had first had sex when they were younger than 14 described that experience as coerced, this proportion fell to $15 \%$ among respondents whose age at first intercourse was 14 or 15 , and to $10 \%$ among those who had first had sex at age 16 or older. Differences among the three subgroups were statistically significant.

Figure 1 shows the association between young women's reports of coerced first intercourse and experience of sexual coercion in the last 12 months. Respondents who reported that their first intercourse had been coerced were significantly more likely than those who did not to report that they had experienced recent coercion (36\% vs. 11\%). Because this difference may be attributable in part to cases in which respondents' first and most recent partners were the same person, we further stratified young women by their reported cumulative number of partners. Among respondents who reported having had only one partner-and whose most re-

*Modern methods include oral contraceptives, condoms, spermicides, injectables, IUDs, male and female sterilization and the implant. 
cent partner was therefore presumably also the first partner-those whose first sex had been coerced were significantly more likely to report recent coercion than those whose first sex had not been forced (43\% vs. 7\%). Even among women who reported two or more cumulative partnerswhose first and most recent partners were probably different ${ }^{*}$-the proportion experiencing recent coercion was significantly higher among those who reported coerced first sex than among those who did not (33\% vs. 15\%); this suggests that women whose first intercourse was coerced may be vulnerable to continued sexual coercion, even within subsequent partnerships.

\section{Coerced First Sex and Reproductive Behavior}

Table 1 examines the relationships between coerced first intercourse and current contraceptive use, pregnancy and unintended pregnancy, overall and by marital status. Among all respondents, those who reported coerced first intercourse were significantly less likely than those who did not to be currently using contraceptives (18\% vs. $34 \%$ ). Although a similar pattern appeared among both currently married and unmarried young women, the difference was statistically significant only among the latter subgroup (30\% vs. 50\%).

A significantly higher percentage of young women who had been coerced into first intercourse than of those who had not been coerced reported having ever been pregnant ( $81 \%$ vs. 65\%). This difference was also significant among unmarried women ( $57 \%$ vs. $31 \%$ ) but not among married women, almost all of whom had experienced at least one pregnancy.

To measure unintended pregnancy, ever-pregnant women were asked to recall whether their current or most recent pregnancy had been wanted then, wanted later or unwanted. Among ever-pregnant young women, a significantly higher percentage of those who reported coerced first sex than of those who did not indicated that their current or most recent pregnancy had been unintended (52\% vs. $37 \%$ ). This differential was of borderline significance among currently married young women (45\% vs. 29\%, $\mathrm{p}=.069$ ), and was not statistically significant among unmarried young women.

Further analysis revealed that among all ever-pregnant respondents, both unwanted and mistimed pregnancies were more common among young women who had been coerced than among those who had not ( $15 \%$ vs. $6 \%$ and $36 \%$ vs. $31 \%$, respectively; data not shown).

\section{Coerced First Sex and Sexual Risk Behavior}

Table 2 shows distributions of married and unmarried women by three indicators of sexual risk behavior-reported cumulative number of sexual partners, condom use at last sex and the consistency of condom use during the last six months-according to experience of coerced first inter-

*For women reporting two or more cumulative partners, some current primary partners may also have been the initial sexual partners.

\begin{tabular}{|c|c|c|c|c|c|c|}
\hline \multirow[t]{3}{*}{ Measure } & \multicolumn{2}{|l|}{ All } & \multicolumn{2}{|l|}{ Married } & \multicolumn{2}{|c|}{ Unmarried } \\
\hline & \multicolumn{2}{|c|}{ Coerced first sex } & \multicolumn{2}{|c|}{ Coerced first sex } & \multicolumn{2}{|c|}{ Coerced first sex } \\
\hline & $\begin{array}{l}\text { Yes } \\
(\mathrm{N}=83)\end{array}$ & $\begin{array}{l}\text { No } \\
(\mathrm{N}=492)\end{array}$ & $\begin{array}{l}\text { Yes } \\
(\mathrm{N}=46)\end{array}$ & $\begin{array}{l}\text { No } \\
(\mathrm{N}=249)\end{array}$ & $\begin{array}{l}\text { Yes } \\
(\mathrm{N}=37)\end{array}$ & $\begin{array}{l}\text { No } \\
(\mathrm{N}=243)\end{array}$ \\
\hline \multicolumn{7}{|c|}{ Cumulative no. of partners } \\
\hline 1 & 33.7 & 49.2 & 32.6 & 46.2 & 35.1 & 52.3 \\
\hline$\geq 2$ & 66.3 & 50.8 & 67.4 & 53.8 & 64.9 & 47.7 \\
\hline$\chi^{2} p$-value & .001 & & .088 & & .052 & \\
\hline \multicolumn{7}{|c|}{ Condom use at last sex } \\
\hline No & 86.7 & 67.1 & 95.6 & 94.8 & 75.7 & 38.4 \\
\hline Yes & 13.3 & 32.9 & 4.4 & 5.2 & 24.3 & 61.6 \\
\hline$\chi^{2} p$-value & .004 & & .804 & & .001 & \\
\hline \multicolumn{7}{|c|}{ Consistent condom use over last 6 mos. $\dagger$} \\
\hline Always & 7.2 & 25.3 & 0.0 & 1.6 & 16.2 & 49.6 \\
\hline Sometimes & 18.1 & 15.5 & 8.7 & 11.2 & 29.7 & 19.8 \\
\hline Never & 74.7 & 59.3 & 91.3 & 87.2 & 54.1 & 30.6 \\
\hline$\chi^{2} p$-value & .001 & & .592 & & .001 & \\
\hline Total & 100.0 & 100.0 & 100.0 & 100.0 & 100.0 & 100.0 \\
\hline
\end{tabular}

†Total N for this measure was 574 .

course. Overall, a modest but significant difference in cumulative number of partners was evident between respondents who had been coerced and those who had not: Young women whose first intercourse had been coerced were significantly more likely than those who had not been coerced to report having had two or more sexual partners (66\% vs. 51\%). This difference was of borderline statistical significance among both married and unmarried respondents.

A significant relationship was evident between coerced first intercourse and condom use at last sex: Respondents who reported coerced first intercourse were less likely than those who did not to say that they had used a condom at last intercourse (13\% vs. 33\%). Young women who reported coerced first sex were also less likely than other respondents to report that they had always used condoms with all sexual partners in the preceding six months (7\%

\begin{tabular}{|c|c|c|c|c|c|c|}
\hline \multirow[t]{3}{*}{ Symptom } & \multicolumn{2}{|l|}{ All } & \multicolumn{2}{|c|}{ Married } & \multicolumn{2}{|c|}{ Unmarried } \\
\hline & \multicolumn{2}{|c|}{ Coerced first sex } & \multicolumn{2}{|c|}{ Coerced first sex } & \multicolumn{2}{|c|}{ Coerced first sex } \\
\hline & $\begin{array}{l}\text { Yes } \\
(\mathrm{N}=83)\end{array}$ & $\begin{array}{l}\text { No } \\
(\mathrm{N}=492)\end{array}$ & $\begin{array}{l}\text { Yes } \\
(\mathrm{N}=46)\end{array}$ & $\begin{array}{l}\text { No } \\
(\mathrm{N}=249)\end{array}$ & $\begin{array}{l}\text { Yes } \\
(\mathrm{N}=37)\end{array}$ & $\begin{array}{l}\text { No } \\
(\mathrm{N}=243)\end{array}$ \\
\hline At least one symptom & $42.2^{* * *}$ & 20.5 & $43.5^{*}$ & 28.1 & $40.5^{* * *}$ & 12.8 \\
\hline Lower abdominal pain & $19.3^{* *}$ & 9.4 & 17.4 & 14.1 & $21.6^{* * *}$ & 4.5 \\
\hline Discharge & 10.8 & 7.3 & 8.7 & 10.0 & $13.5^{*}$ & 4.5 \\
\hline Vaginal itching or unpleasant odor & $18.1^{*}$ & 9.8 & 17.4 & 11.7 & $18.9^{*}$ & 7.8 \\
\hline Frequent or painful urination & 9.6 & 5.7 & 10.9 & 8.8 & 8.1 & 2.5 \\
\hline Pain during intercourse & 3.6 & 2.9 & 6.5 & 4.0 & 0.0 & 1.7 \\
\hline Genital ulcer & $2.0^{*}$ & 0.6 & 4.4 & 0.8 & 2.7 & 0.4 \\
\hline Genital warts & 2.4 & 1.2 & 2.2 & 1.6 & 2.7 & 0.8 \\
\hline
\end{tabular}

*Difference from those who did not report coerced first sex significant at $p \leq .05$. * Difference from those who did not report coerced first sex significant at $p \leq .01$. ${ }^{* * *}$ Difference from those who did not report coerced first sex significant at $\mathrm{p} \leq .001$. 


\begin{tabular}{|c|c|c|c|c|c|}
\hline $\begin{array}{l}\text { Behavior and } \\
\text { outcome }\end{array}$ & $\begin{array}{l}\text { Current contra- } \\
\text { ceptive use } \\
(\mathrm{N}=575)\end{array}$ & $\begin{array}{l}\text { Condom use } \\
\text { at last sex } \\
(\mathrm{N}=574)\end{array}$ & $\begin{array}{l}\text { Consistent condom use } \\
\text { during last } 6 \text { mos. } \\
(\mathrm{N}=574)\end{array}$ & $\begin{array}{l}\geq 1 \text { genital tract } \\
\text { symptom } \\
(\mathrm{N}=575)\end{array}$ & $\begin{array}{l}\text { Current or most recent } \\
\text { pregnancy unintended } t \\
(\mathrm{~N}=384)\end{array}$ \\
\hline \multicolumn{6}{|c|}{ Coerced first sex } \\
\hline No & 1.00 & 1.00 & 1.00 & 1.00 & 1.00 \\
\hline Yes & $0.47(0.25-0.88)^{*}$ & $0.26(0.12-0.55)^{* * * *}$ & $0.19(0.08-0.50)^{* * *}$ & $2.60(1.57-4.32)^{* * *}$ & $2.06(1.17-3.63)^{*}$ \\
\hline \multicolumn{6}{|c|}{ Education level (yrs.) } \\
\hline$<5$ & 1.00 & 1.00 & 1.00 & 1.00 & 1.00 \\
\hline $5-7$ & $1.34(0.72-2.52)$ & $1.33(0.58-3.04)$ & $2.54(0.79-8.15)$ & $0.97(0.58-1.62)$ & $1.26(0.75-2.12)$ \\
\hline$\geq 8$ & $2.90(1.49-5.63)^{* *}$ & $3.98(1.72-9.26)^{* * * *}$ & $7.38(2.31-23.61)^{* * *}$ & $0.57(0.30-1.08)$ & $1.94(1.00-3.78)^{*}$ \\
\hline \multicolumn{6}{|c|}{ Religious affiliation } \\
\hline Other & 1.00 & 1.00 & 1.00 & 1.00 & 1.00 \\
\hline Catholic & $2.11(1.28-3.45)^{* * *}$ & $1.57(0.90-2.74)$ & $1.82(1.00-3.34)$ & $0.84(0.52-1.36)$ & $1.65(0.97-2.82)$ \\
\hline Muslim & $1.33(0.71-2.50)$ & $1.17(0.57-2.40)$ & $0.78(0.35-1.70)$ & $0.82(0.43-1.54)$ & $1.29(0.65-2.58)$ \\
\hline \multicolumn{6}{|l|}{ Age at first sex } \\
\hline$<14$ & 1.00 & 1.00 & 1.00 & 1.00 & 1.00 \\
\hline 14-15 & $1.22(0.65-2.32)$ & $0.98(0.46-2.09)$ & $1.17(0.49-2.83)$ & $0.73(0.42-1.27)$ & $1.04(0.58-1.88)$ \\
\hline$\geq 16$ & $1.32(0.63-2.78)$ & $1.33(0.56-3.17)$ & $1.74(0.65-4.66)$ & $0.52(0.25-1.09)$ & $0.70(0.32-1.55)$ \\
\hline \multicolumn{6}{|l|}{ Marital status } \\
\hline Unmarried & 1.00 & 1.00 & 1.00 & 1.00 & 1.00 \\
\hline Married & $0.29(0.19-0.44)^{* * *}$ & $0.05(0.03-0.10)^{* * * *}$ & $0.02(0.01-0.06)^{* * *}$ & $1.80(1.15-2.81)^{* *}$ & $0.40(0.24-0.65)^{* * *}$ \\
\hline
\end{tabular}

vs. $25 \%$ ), and were more likely to report that they had never used condoms (75\% vs. 59\%) during that time. Both associations were statistically significant.

Stratification by marital status revealed that the relationships between coerced first sex and both measures of condom use remained significant only among unmarried women. Twenty-four percent of unmarried women who reported coerced first sex had used a condom at last sex, compared with $62 \%$ of those who reported no coercion at that time. When asked about condom use during the last six months, $16 \%$ of women who had been coerced had always used them, 30\% had used them sometimes and 54\% had never used them. Among women who had not been coerced, those proportions were 50\%, 20\% and 31\%. Condom use among married young women was extremely low in both coercion categories.

\section{Coerced First Sex and Genital Tract Symptoms}

Overall, the proportion of adolescent women who reported at least one genital tract symptom was twice as high among those who had experienced coerced first sex as among those had not ( $42 \%$ vs. $21 \%$ ), a statistically significant difference (Table 3, page 159). Moreover, the prevalence of specific symptoms was consistently higher among young women whose first intercourse had been coerced than among other respondents (2-19\% vs. 1-10\%); differences between the two groups were statistically significant for lower abdominal pain, vaginal itching or unpleasant odor, and genital ulcers. The proportion of married respondents who reported at least one genital symptom was significantly higher among young women whose first intercourse had been coerced than among others (44\% vs. $28 \%$ ). This relationship was even stronger among unmarried respondents ( $41 \%$ vs. 13\%).

\section{Multivariate Analyses}

The relationships of risk behaviors and reproductive health outcomes with coerced first sex that were found at the bivariate level remained significant in the multivariate models, which controlled for education, religious affiliation, age at first sex and marital status (Table 4). Compared with young women who did not report coerced first intercourse, those who did had significantly reduced odds of current contraceptive use (odds ratio, 0.5 ). This negative relationship was even stronger for condom use at last intercourse (0.3) and for consistent condom use in the last six months (0.2). The risk of reporting one or more genital tract symptom was significantly higher among women who had experienced coerced first intercourse than among those who had not (2.6). Among ever-pregnant women, coercion was associated with significantly elevated odds of reporting the current or most recent pregnancy as unintended (2.1). In addition, having had eight or more years of schooling was strongly associated with contraceptive use, condom use at last sex and consistent condom use in the last six months (2.9-7.4). Catholic women had significantly higher odds of reporting current contraceptive use relative to those in the "other" religious affiliation category (2.1). Compared with unmarried respondents, currently married women had significantly decreased odds of current contraceptive use, condom use at last sex, consistent condom use and unintended pregnancy (0.02-0.40), and had significantly increased odds of reporting at least one genital tract symptom (1.8).

\section{DISCUSSION}

At least three plausible mechanisms have been put forward to explain the potential association between physical or sexual violence and adverse reproductive health out- 
comes. One mechanism concerns the direct biological effects of coerced intercourse, such as unintended pregnancy, abortion, and STIs and their sequelae. ${ }^{26} \mathrm{~A}$ second mechanism suggests that physical or sexual violence may disempower women in negotiating safer sex and may negatively affect protective behaviors related to fertility regulation and STIs, including contraceptive use, STI treatment seeking, use of condoms and ability to affect their partners' risk-taking behavior. ${ }^{27} \mathrm{~A}$ third mechanism relates to sexual coercion and abuse during childhood, which may increase women's propensity to subsequently engage in high-risk sexual behavior during adolescence. ${ }^{28}$

Whether an indicator of subsequent elevated risk or a direct contributing factor, coerced first sex was strongly and systematically associated with a number of adverse reproductive health outcomes in our study: decreased contraceptive use, condom nonuse at last sex, inconsistent condom use during the last six months, unintended pregnancy, and genital tract symptoms, which may indicate the presence of an STI. Other research from Rakai has highlighted the significant association between coerced first intercourse and young women's risk of HIV infection. ${ }^{29}$ That these associations may arise not solely from coercion at first sex, but from repeated acts of coerced intercourse, is suggested by our finding that young women whose first intercourse had been coerced were at increased risk of recent coercion, regardless of whether their first and current partners were the same person.

This is one of the first developing country studies to present evidence on the association between coerced first intercourse and adverse reproductive health outcomes among adolescent women; still, several limitations merit discussion. First, underreporting associated with respondents' reluctance to acknowledge a highly sensitive experience may have led to an underestimate of the prevalence of sexual coercion. However, the prolonged exposure of respondents to the Rakai Project and its interviewers over the past decade, the rapport that has been established between respondents and interviewers as a result of this exposure, and the safeguards for privacy and confidentiality of information are likely to have increased respondents' willingness to discuss the issue of sexual coercion. The order of questions on coerced first sex may also have contributed to underreporting: Respondents were initially asked whether their first sex had been coerced, which left them to define what constitutes coercion. Only those who answered affirmatively were asked about the range of coercive acts that accompanied first intercourse. If the order of questions had been reversed, more women might have identified coercive actions that had accompanied first sex and subsequently defined that experience as "coerced."

Second, our study is limited by the measurement of several reproductive health outcomes included in the analyses. For example, retrospective assessments of pregnancy intendedness often underestimate the prevalence of unintended pregnancy, largely because mothers tend to rationalize unintended births as having been intended. ${ }^{30}$ Moreover, the correspondence between self-reported genital tract symptoms and clinically identified or laboratory-confirmed gynecological morbidity has been shown to be quite low. ${ }^{31}$ Nevertheless, self-reported symptoms are useful in assessing women's perceptions of gynecological problems and in many cases may indicate the presence of an STI. A related concern is that women with adverse reproductive health outcomes (e.g., unintended pregnancy and genital tract symptoms) may be more likely to view their first sexual experience in a negative light and to classify it as coerced. Although we cannot rule out this possibility, the absence of such response bias is supported by the findings from another study in Rakai, which revealed that the relationship between coerced first intercourse and HIV infection was statistically significant whether or not women were aware of their HIV status. ${ }^{32}$

Finally, we are unable to assume temporality or causality in the relationships between sexual coercion and the outcomes considered. Many of these observed associations may be attributable to unmeasured antecedent factors (e.g., unstable family environment or economic adversity) that both place young women at increased risk of sexual coercion during adolescence and increase their vulnerability to subsequent adverse reproductive health behaviors or outcomes. Moreover, the cross-sectional nature of the data complicates our ability to establish temporality or causality in many of the observed relationships, ${ }^{*}$ although this issue is addressed somewhat by our consideration of coercion at first intercourse as the exposure variable. Before assumptions of causality can be attributed to these associations, further quantitative and qualitative research is required to elucidate the specific pathways through which sexual coercion increases young women's vulnerability to adverse outcomes.

Our findings highlight the magnitude of the problem of sexual coercion among adolescent women in this rural Ugandan population. However, coerced intercourse represents only one of the more extreme forms of sexual abuse. Had the survey also included questions about attempted sexual coercion and forms of sexual abuse other than penetrative intercourse, the prevalence of sexual violence in our study would most likely have been substantially higher. In addition, it is noteworthy that the levels of coerced intercourse reported here are significantly lower than those reported by many studies from Sub-Saharan Africa. Other research suggests that the prevalence of sexual coercion-at least at first intercourse-appears to have significantly declined across successive age cohorts in Rakai. ${ }^{33}$ It is of interest to consider the role this trend may have played in the apparent decrease in HIV prevalence that has recently taken place in Uganda. ${ }^{34}$

The issue of sexual coercion and violence remains largely overlooked within current family planning and reproductive health service programs. Although sexual abuse is

*Most notably, it was impossible to determine from the data whether sexual coercion had led to unintended pregnancy or whether young women's partners had reacted to unintended pregnancy with physical or sexual violence. 
an important social and public health issue in its own right, the results of our study strongly suggest that such behavior has major adverse consequences for important aspects of young women's sexual and reproductive health. Our study highlights the potential importance of addressing the issue of sexual coercion and violence as an integral component of current reproductive health service programs.

\section{REFERENCES}

1. World Health Organization (WHO), Violence Against Women: A Priority Health Issue, Geneva: WHO, 1997.

2. van der Straten A et al., Sexual coercion, physical violence, and HIV infection among women in steady relationships in Kigali, Rwanda, AIDS and Behavior, 1998, 2(1):61-73; Watts C et al., Withholding of sex and forced sex: dimensions of violence against Zimbabwean women, Reproductive Health Matters, 1998, 6(12):57-65; Coker AL and Richter DL, Violence against women in Sierra Leone: frequency and correlates of intimate partner violence and forced sexual intercourse, African Journal of Reproductive Health, 1998, 2(1):61-72; Haj-Yahia MM and Edleson EL, Predicting the use of conflict resolution tactics among engaged Arab-Palestinian men in Israel, Journal of Family Violence, 1994, 9(1):47-62; Ilkkaracan P and Women for Women's Human Rights, Exploring the context of women's sexuality in Eastern Turkey, Reproductive Health Matters, 1998, 6(12):66-75; Ellsberg M et al. Candies in hell: women's experiences of violence in Nicaragua, Social Science \& Medicine, 2000, 51(11):1595-1610; and Martin SL et al., Sexual behaviors and reproductive health outcomes: associations with wife abuse in India, Journal of the American Medical Association, 1999, 282(20):1967-1972.

3. Abma J, Driscoll A and Moore K, Young women's degree of control over first intercourse: an exploratory analysis, Family Planning Perspectives, 1998, 30(1):12-18; Dickson N et al., First sexual intercourse: age, coercion, and later regrets reported by a birth cohort, BMJ, 1998, 316(7124):29-33; Ajuwon A et al., Experience of sexual coercion among adolescents in Ibadan, Nigeria, African Journal of Reproductive Health, 2001, 5(3):120-131; and Mulugeta E et al., Prevalence and outcomes of sexual violence among high school students, Ethiopian Medical Journal, 1998, 36(3):167-174.

4. Glover EK et al., Sexual health experiences of adolescents in three Ghanaian towns, International Family Planning Perspectives, 2003 29(1):32-40; Somse P et al., Multiple sexual partners: results of a national HIV/AIDS survey in the Central African Republic, AIDS, 1993, 7(4):579-583; Buga GA et al., Sexual behaviour, contraceptive practice and reproductive health among school adolescents in rural Transkei, South African Medical Journal, 1996, 86(5):523-527; and Matasha E et al., Sexual and reproductive health among primary and secondary school pupils in Mwanza, Tanzania: need for intervention, AIDS Care, 1998, 10(5):571-582.

5. Rwenge M, Sexual risk behaviors among young people in Bamenda, Cameroon, International Family Planning Perspectives, 2000, 26(3):118123 \& 130; and Caceres CF et al., Sexual coercion among youth and young adults in Lima, Peru, Journal of Adolescent Health, 2000, 27(5): 361-367.

6. Ajuwon AJ et al., Perceptions of sexual coercion: learning from young people in Ibadan, Nigeria, Reproductive Health Matters, 2001 , 9(17):128-136; Hulton LA, Cullen R and Khalokho SW, Perceptions of the risks of sexual activity and their consequences among Ugandan adolescents, Studies in Family Planning, 2000, 31(1):35-46; and Wood Ket al., "He forced me to love him": putting violence on adolescent sexual health agendas, Social Science \& Medicine, 1998, 47(2):233-242.

7. Heise L, Moore K and Toubia N, Sexual Coercion and Reproductive Health: A Focus on Research, New York: Population Council, 1995; Garcia-Moreno $C$ and Watts C, Violence against women: its importance for HIV/AIDS, AIDS, 2000, 14(3):S253-S265; and Krug EG et al., eds., World Report on Violence and Health, Geneva: WHO, 2002.

8. Brown SS and Eisenberg L, The Best Intentions: Unintended Pregnancy and the Well-Being of Children and Families, Washington, DC: National Academy Press, 1995; Cokkinides V et al., Physical violence during pregnancy: maternal complications and birth outcomes, Obstetrics $\&$ Gynecology, 1999, 93(5):661-666; Curry MA et al., Effects of abuse on maternal complications and birth weight in adult and adolescent women, Obstetrics \& Gynecology, 1998, 92(4):530-534; Dietz PM et al., Unintended pregnancy among adult women exposed to abuse or household dysfunction during their childhood, Journal of the American Medical Association, 1999, 282(14):1359-1364; Gazmararian JA et al., The relationship between pregnancy intendedness and physical violence in mothers and newborns, Obstetrics \& Gynecology, 1995, 85(6): 1031-1038; Boyer D and Fine D, Sexual abuse as a factor in adolescent pregnancy and child maltreatment, Family Planning Perspectives, 1992, 24(1):4-19; Butler RJ and Burton LM, Rethinking teenage childbearing: is sexual abuse a missing link? Family Relations, 1990, 39(2): 73-80; Roosa MW et al., The relationship of childhood sexual abuse to teenage pregnancy, Journal of Marriage and Family, 1997, 59(1): 119-130; and Stewart D et al., Physical abuse during pregnancy, Canadian Medical Association Journal, 1993, 149(9):1257-1263.

9. Jewkes R et al., Relationship dynamics and teenage pregnancy in South Africa, Social Science \& Medicine, 2001, 52(5):733-744; Hof C and Richters A, Exploring the intersections between teenage pregnancy and gender violence: lessons from Zimbabwe, African Journal of Reproductive Health, 1999, 3(1):51-65; and Martin SL et al., 1999, op. cit. (see reference 2 )

10. Bawah AA et al., The impact of family planning on gender relations in Northern Ghana, Studies in Family Planning, 1999, 30(1):54-66; Folch-Lyon E et al., Focus group and survey research on family planning in Mexico, Studies in Family Planning, 1981, 12(2):409-432; and Martin SL et al., 1999, op. cit. (see reference 2).

11. Eby KK et al., Health effects on experiences of sexual violence for women with abusive partners, Health Care for Women International, 1995, 16(6):563-575; Schei B, Physically abusive spouse-a risk factor of pelvic inflammatory disease, Scandinavian Journal of Primary Health Care, 1991, 9(1):41-45; Schei B, Psycho-social factors in pelvic pain: a controlled study of women living in physically abusive relationships, Acta Obstetricia et Gynecologia Scandinavica, 1990, 69(1):67-71; and Schei B and Bakketeig LS, Gynaecological impact of sexual and physical abuse by spouse: a study of a random sample of Norwegian women, British Journal of Obstetrics and Gynaecology, 1989, 96(12): 1379-1383

12. Amaro H et al., Violence during pregnancy and substance abuse, American Journal of Public Health, 1990, 80(5):575-579; and Martin SL et al., Domestic violence and sexually transmitted diseases: the experience of prenatal care patients, Public Health Reports, 1999, 114(3): 262-268

13. Maman S et al., The intersections of HIV and violence: directions for future research and interventions, Social Science $\&$ Medicine, 2000, 50(4):459-478; and Garcia-Moreno C and Watts C, 2000, op. cit. (see reference 7).

14. Maman S et al., HIV-positive women report more lifetime partner violence: findings from a voluntary counseling and testing clinic in Dar es Salaam, Tanzania, American Journal of Public Health, 2002, 92(8): 1331-1337; van der Straten A et al., Couple communication, sexual coercion and HIV risk reduction in Kigali, Rwanda, AIDS, 1995, 9(8):935-944; Quigley M et al., Case-control study of risk factors for incident HIV infection in rural Uganda, Journal of Acquired Immune Deficiency Syndrome, 2000, 23(5):418-425.

15. Choi KH et al., Sexual harassment, sexual coercion, and HIV risk among U.S. adults 18-49 years, AIDS and Behavior, 1998, 2(1):33-40; $\mathrm{He} \mathrm{H}$ et al., Violence and HIV sexual risk behaviors among female sex partners of male drug users, Women \& Health, 1998, 27(1/2):161-175; and Somse P et al., 1993, op. cit. (see reference 4).

16. He H et al., 1998, op. cit. (see reference 15); Kalichman SC et al., Sexual coercion, domestic violence, and negotiating condom use among low-income African American women, Journal of Women's Health, 1998, 7(3):371-378; Wingood GM et al., Adverse consequences of intimate partner abuse among women in non-urban domestic violence shelters, American Journal of Preventive Medicine, 2000, 19(4):270-275; and Wingood GM and DiClemente RJ, The effects of an abusive primary partner on the condom use and sexual negotiation practices of African-American women, American Journal of Public Health, 1997, 87(6):1016-1018.

17. Ntozi J and Lubega M, Patterns of sexual behaviour and the spread of AIDS in Uganda, in Dyson T, ed., Sexual Behaviour and Networking: 
Anthropological and Socio-Cultural Studies on the Transmission of HIV, Liege, Belgium: Derouaux-Ordina Publications, 1991; and OlowoFreers BP and Barton TG, In Pursuit of Fulfillment: Studies of Cultural Diversity and Sexual Behaviour in Uganda, Kisubi, Uganda: Marianum Press, 1992.

18. Uganda Bureau of Statistics (UBOS) and ORC Macro, Uganda Demographic and Health Survey 2000-2001, Calverton, MD, USA: UBOS and ORC Macro.

19. Blanc AB and Way A, Sexual behavior, contraceptive knowledge, and use, Studies in Family Planning, 1998, 29(2):106-116.

20. Hulton L, Cullen R and Khalokho SW, 2000, op. cit. (see reference $6)$.

21. Wawer MJ et al., Control of sexually transmitted diseases for AIDS prevention in Uganda: a randomised community trial, Lancet, 1999 , 353(9152):525-535.

22. Ibid.

23. Lutalo $\mathrm{T}$ et al., Trends and determinants of contraceptive use in Rakai District, Uganda, 1995-98, Studies in Family Planning, 2000, 31(3):217-227.

24. Koenig MA et al., Domestic violence in Rakai, Uganda: evidence from a community-based survey, Bulletin of the World Health Organization, 2003, 81(1):53-60.

25. STATA Corporation, STATA Statistical Software, 2001, release 8.1.

26. Heise L, Moore K and Toubia N, 1995, op. cit. (see reference 7).

27. Ibid.; and Maman S et al., 2000, op. cit. (see reference 13).

28. Handwerker WP, Gender power differences between parents and high-risk sexual behavior by their children: AIDS/STD risk factors extend to a prior generation, Journal of Women's Health, 1993, 2(3):301316; and Maman S et al., 2000, op. cit. (see reference 13).

29. Koenig MA et al., First coercive sex and subsequent HIV risk among young women in Rakai, Uganda, unpublished paper, 2004.

30. Santelli J et al., The measurement and meaning of unintended pregnancy, Perspectives on Sexual and Reproductive Health, 2003, 35(2): 94-101; and Joyce T, Kaestner R and Korenman S, On the validity of retrospective assessments of pregnancy intention, Demography, 2002, 39(1):199-213.

31. Jejeebhoy SJ, Koenig MA and Elias C, Reproductive Tract Infections and Other Gynaecological Disorders, Cambridge, UK: Cambridge University Press, 2003.

32. Koenig MA et al., 2004, op. cit. (see reference 29).

33. Koenig MA et al., Risk and protective factors for coercive first sex in Rakai, Uganda, paper presented at the Annual Meeting of the Population Association of America, Minneapolis, MN, USA, May 1-3, 2003.

34. Kilian A et al., Reduction in risk behavior provides the most consistent explanation of declining HIV-1 prevalence in Uganda, AIDS, 1999, 13(3):391-398.

\section{RESUMEN}

Contexto: Si bien hay un mayor reconocimiento del ámbito y significado del sexo forzado que experimentan las adolescentes en los países en desarrollo, son limitadas las pruebas que existen sobre sus consecuencias con relación a la salud reproductiva. Métodos: En 2001-2002, se entrevistaron a 575 mujeres con experiencia sexual de 15-19 años como parte de un proyecto continuo de monitoreo en el distrito de Rakai, en una zona rural de Uganda. Se utilizaron pruebas de chi-cuadrado y análisis de regresión logística para investigar la relación entre la primera relación sexual mantenida en condiciones de coerción y determinados comportamientos y consecuencias sobre la salud reproductiva.

Resultados: El 14\% de las mujeres jóvenes indicaron que su primera relación sexual había sido mantenida en una situación de coerción. Después de haber tomado en cuenta las características demográficas de las entrevistadas, las jóvenes que indicaron haber mantenido relaciones sexuales en situación de coerción eran significativamente menos proclives que otras mujeres a ser usuarias actuales de anticonceptivos modernos; a haber utilizado un condón durante su última relación; y a haber usado este anticonceptivo en forma continua durante los últimos seis meses. Asimismo, se mostraron más proclives a indicar que su último embarazo era no planeado (entre las mujeres que alguna vez estuvieron embarazadas) y que habian tenido uno o más síntomas de infección en el tracto genital.

Conclusiones: La coerción durante la primera relación sexual es un importante problema social y de salud pública que tiene serias repercusiones en la salud reproductiva y el bienestar de las mujeres jóvenes. Las medidas que se adopten para mejorar la salud reproductiva de las adolescentes deben encarar directamente la cuestión de la coerción sexual.

\section{RÉSUMÉ}

Contexte: Malgré la reconnaissance grandissante de l'ampleur et de la signification de la contrainte sexuelle subie par les adolescentes des pays en développement, la constatation de ses conséquences sur la santé reproductive demeure limitée.

Méthodes: Un échantillon de 575 femmes sexuellement expérimentées de 15 à 19 ans a été interviewé en 2001-2002 dans le cadre du projet de surveillance continue de la région ougandaise rurale de Rakai. La recherche des associations entre premiers rapports sexuels vécus sous la contrainte et certains comportements et issues de santé reproductive a été menée par tests chi carré et régressions logistiques.

Résultats: Quatorze pour cent des jeunes femmes ont déclaré avoir subi leurs premiers rapports sexuels sous la contrainte. Compte tenu des effets des caractéristiques démographiques des répondantes, les jeunes femmes ayant déclaré une première expérience sexuelle vécue sous la contrainte étaient significativement moins susceptibles que les autres de pratiquer une méthode contraceptive moderne au moment de l'entrevue, d'avoir utilisé le préservatif lors de leurs derniers rapports sexuels et d'en avoir fait usage régulièrement durant les six mois précédents. Elles étaient du reste plus susceptibles de qualifier leur dernière grossesse de non planifiée (parmi les femmes qui avaient jamais été enceintes) et de déclarer au moins un symptôme d'affection de l'appareil reproductif.

Conclusions: Les premiers rapports sexuels vécus sous la contrainte posent un sérieux problème social et de santé publique, susceptible de répercussions graves sur la santé reproductive et le bien-être des jeunes femmes. Les interventions d'amélioration de la santé reproductive des adolescentes doivent confronter de manière directe le problème de la contrainte sexuelle.

\section{Acknowledgments}

The authors gratefully acknowledge the assistance of Mark Emerson, Feng Zhao, Eva Bazant and Mary Shields in the preparation of this paper.

Author contact: mkoenig@jhsph.edu 